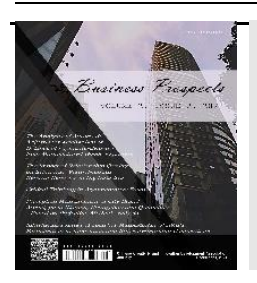

Business Prospects

Chinese Creativity and Innovation Development Association (CCIDA)

journal homepage: www.ccidanpo.org

https://doi.org/10.52288/bp.27089851.2021.12.16

\title{
The Effect of Exhibition on Urban Economic Development
}

\author{
Ting-Jun Chang 1 , * \\ ${ }^{1}$ School of International Business, Xiamen University Tan Kah Kee College \\ *Correspondence: 869087373@qq.com*
}

Received: 2021.08.05; Accepted: 2021.08.30; Published: 2021.12.01

\begin{abstract}
Along with the process of economic globalization, international exhibition concentrates the flow of people, logistics and information, which is in line with the trend of economic globalization. Exhibition economy is an important part of the global economy, and the study of exhibition will play a decisive role in regional economic development. This paper analyzes the influence of the number of exhibition activities, exhibition area, number of meeting activities and the number of meeting participants on direct economic benefits, induced economic benefits and total economic benefits on Xiamen City using multiple regression analysis. The results demonstrate the importance and difference of exhibitions and meetings to the economic development of Xiamen City.
\end{abstract}

Keywords: Exhibition; Meeting; Urban Economy; Multiple Regression Analysis

\section{Foreword}

Xiamen is an open and inclusive city. It was one of the first cities in China to open to the outside world. In the 1970s and 1980s, Xiamen was selected as a special economic zone. With its unique geographical location and open and inclusive urban culture, Xiamen's meeting and exhibition industry is also developing along with the reform and opening. Since the 1980s, Xiamen's exhibition industry has experienced more than 30 years of development and is also one of the earliest cities in China to attach importance to the development of exhibition.

Exhibitions play an important part of Xiamen's economy. Exhibitions can be further divided into meetings and exhibitions. The holding of exhibition brings Xiamen direct economic benefits. In 2019, Xiamen's meeting and exhibition industry achieved a total economic benefit of 45.09 billion Yuan and with an annual growth rate of $12 \%$. Among them, the economic benefits of exhibition industry reached 17.52 billion Yuan and the economic benefits of meeting industry reached 27.57 billion Yuan. However, due to the traffic conditions, hardware facilities, management and service level and other subjective and objective factors, Xiamen exhibition development potential has not been fully tapped, its resource endowment and exhibition performance is far from commensurate, from the overall view, the development of the exhibition industry is still in the primary stage of development (Zhan, 2009). As an important part of modern service industry, exhibitions are a new driving force for economic growth in many cities. Study of exhibition and its economic benefits will be of great importance to Xiamen's urban economic development.

\section{International Exhibitions and Related}

\subsection{The Concept of International Exhibition}

International exhibition refers to the collective material and cultural exchange activities formed by many people gathered in a certain geographical space. The exhibition of a specific theme refers to the gathering of many people around a specific theme in a specific a broad sense, exhibition is a general term for conferences, exhibitions, festival events and various industries/industry-related exhibitions. Conference, exhibition, exposition, trade fair, trade fair, exhibition and so on are the basic forms of exhibition activities. World Expo is the most typical exhibition activities. At present, the domestic exhibition industry chain has been quite complete. 


\subsection{Types of Exhibitions}

Exhibitions are divided into meetings and exhibitions. Meetings focus on time and process and reflect characteristics. Exhibitions are market oriented, while meetings are facilities oriented. Exhibitions are very repetitive; meetings are very repetitive. Many exhibitions are held every year, and some big ones are held every two or even four years. The exhibition requires a larger space and a longer use time, plus the application for entering and preparing the exhibition hall, the time will be longer. The venue of the meeting is scattered and the time is relatively short, and the time to enter the hall is not long.

\subsection{Exhibition Economic Benefits and Related}

As a cross-industry and cross-field modern service industry, exhibition brings together a huge flow of people, logistics, information flow and capital flow. It plays an important role in promoting national economy and social progress and has the effect that one industry leads a hundred industries. Xiamen has formed an industrial chain of design and construction, security, transportation, hotel, catering, tourism, retail, entertainment, insurance, consulting, communications, network, advertising, media, printing, and publishing, with conference and exhibition enterprises as the leading and conference and exhibition venues as the core.

According to the influence of the exhibition industry of convention and exhibition industry chain income transfer, exhibition economy benefits can be divided into direct income (including hall, conference room rental income, booth, design structures, revenue, etc.), indirect income (including traffic, accommodation, catering, entertainment, shopping, communication, travel, etc.) and drive revenue (including direct and indirect income of upstream and downstream industry drive, etc.).

This paper uses the number of exhibition activities, exhibition area, the number of meeting activities and the number of participants to study its impact on the exhibition direct economic benefits, induced benefits, and total economic benefits (Wu, 2016). Among them, with the increase of the number of exhibition activities, the positive influence of direct economic benefits on the total benefits is far greater than that of induced economic benefits; The exhibition area has the opposite effect. With the increase of the exhibition area, the effect of induced benefit on the total economic benefit is greater than that of direct benefit. In the number of meeting activities, the difference between the two is small, but with the increase of the number of participants, the contribution of induced benefits to the total economic benefits is much greater than that of direct benefits.

\subsection{Xiamen Exhibition Profile}

Xiamen is the first city to attach importance to the convention and exhibition industry in China. Xiamen's convention and exhibition industry has been developing with the reform and opening. Xiamen has perfect exhibition facilities and is one of the few cities in China that have both large and modern exhibition and conference centers. Xiamen took the lead in the implementation of the exhibition incentive policy in 2003, and expanded the scope of support and incentive to the conference industry in 2008 (Zheng, 2017).

In 2019, Xiamen City gave full play to the guidance and leverage of policies, further optimized the policies of the exhibition industry, and issued a series of new policies, interpretation of supporting policies and detailed rules for implementation and application. In 2019, Xiamen's exhibition industry developed steadily, the overall number of exhibitions increased, and the exhibition area increased slightly. A total of 236 exhibitions were held in Xiamen, with an annual growth of $3.06 \%$. The annual exhibition area of 2,403,000 square meters, an annual growth of $1 \%$.

During the year of 2019, the exhibition attracted 110,200 overseas exhibitors and 461,300 domestic exhibitors from more than 150 countries and regions around the world, with a total audience of 5,212,400 and 2,295,100 domestic and overseas exhibitors in Xiamen. In 2019, 25 new exhibitions will be held, among which 8 exhibitions with a scale of more than 10,000 square meters will be held for the first time, showing a good prospect and potential, and playing an important role in the development of relevant industries and market expansion in Xiamen.

At the same time, the Xiamen conference market in 2019 is relatively active and has a fast growth rate. A total of 9,978 commercial meetings with more than 50 participants were held in the city, with an annual increase of $7.73 \%$. In 2019, the total number of arrivals in Xiamen reached 2.0504 million, with an annual growth of $8.88 \%$. In the whole year, about 10.018 million people stayed in Xiamen, with a year-on-year growth of $3.95 \%$ (Zheng, 2019). 


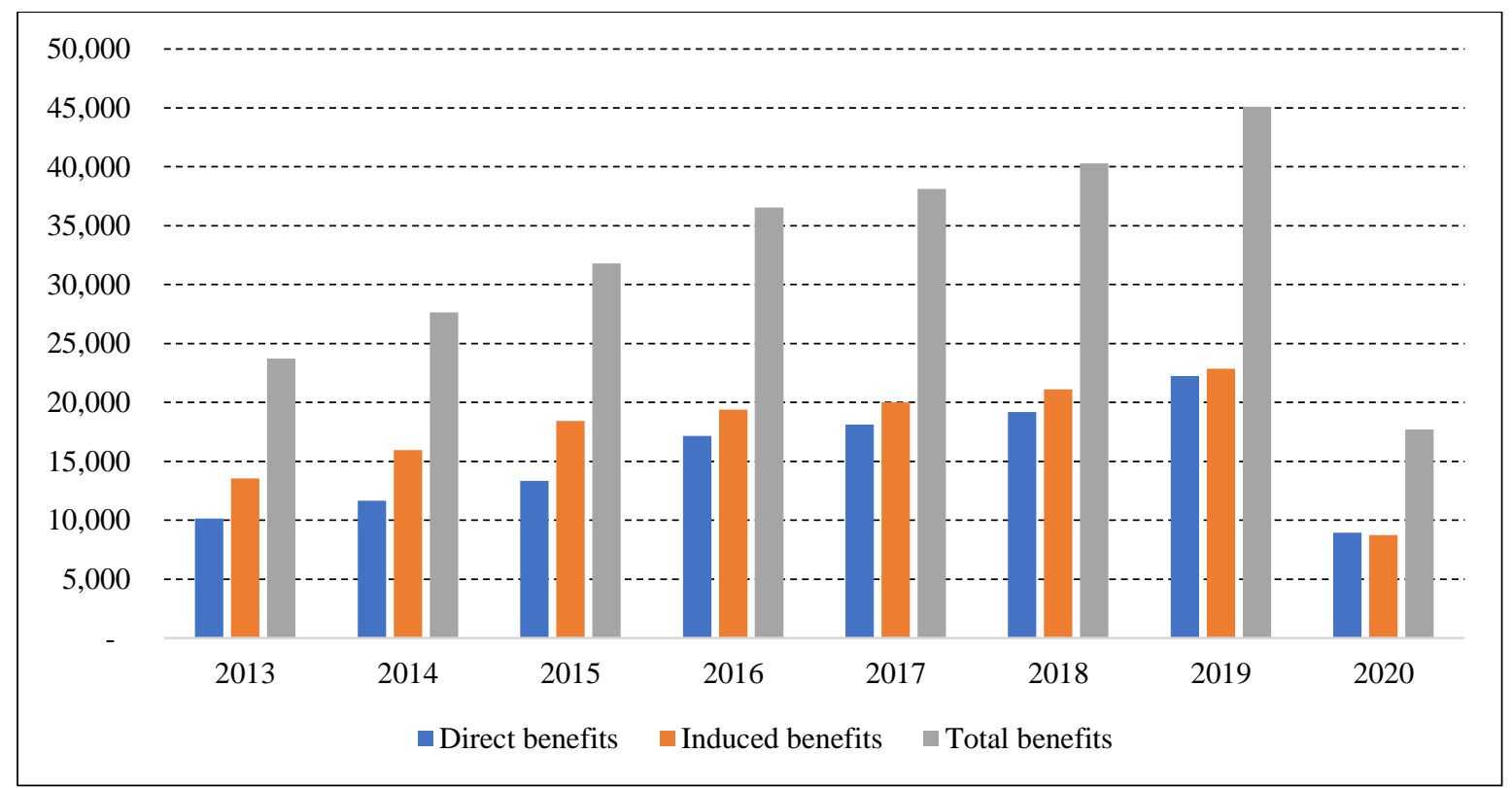

Data Sources: Xiamen Convention and Exhibition Industry Development Report

Figure 1. Direct benefits, induced benefits, and total benefits of Xiamen exhibition. from 2013 2020 (in million Yuan)

In 2020, however, the exhibition industry of Xiamen has been hit hard by the COVID-19. More than one hundred different kinds of exhibitions were cancelled, with a total exhibition area of 1.1789 million square meters or $50.8 \%$ lower than the previous year. For commercial conferences, the number of cancellations is 3,289 (more than 50\%), or 67.0\% lower than the previous year. The total number of participants was 603,800, or $70.5 \%$ lower than the previous year. The overall economic benefit of exhibition was 17.694 billion Yuan, or $60.7 \%$ lower than the previous year (Zheng, 2020).

\section{The Empirical Analysis}

\subsection{Study Design and Data}

This paper studies the influence of the number of exhibitions, the exhibition area, the number of meetings and the number of meeting participants on the direct economic benefits, induced economic benefits and total economic benefits of Xiamen City by distinguishing the meetings and exhibitions. The data came from the annual report of Xiamen exhibition industry's official website.

Multiple regression analysis is used applying the number of exhibitions, the exhibition area, the number of meetings and the number of meeting participants as the independent variables, while direct economic benefits, exhibition induced economic benefits and exhibition total economic benefits of the exhibitions are dependent variables. The data of direct economic benefits and induced economic benefits of exhibition in 2019 and 2020 are not available. The ratio of direct economic benefits and induced economic benefits of exhibition from 2013 to 2018 to the total economic benefits of exhibition is therefore used as a proxy to estimate through extrapolation method.

\subsection{The Empirical Results}

Model results for the effects of the number of exhibitions, the exhibition area, the number of meetings and the number of meeting participants on direct economic benefits, exhibition induced economic benefits and exhibition total economic benefits of the exhibitions are presented in Table 1.

The model of direct effects demonstrates that the number of exhibition activities has positive impact, for any one unit increase in exhibition will bring 55.83 million Yuan to Xiamen as direct benefits. For any one unit $\left(10,000 \mathrm{~m}^{2}\right)$ increase in the area of exhibition, however, will decrease 88.72 million Yuan to Xiamen as direct benefits. As of the meeting activities, for any one unit increase in the number of meeting will bring 2.75 million Yuan to Xiamen as direct benefits. The effects will be offset by the number of participants as any one unit (10,000 persons) increase in the number of participants will decrease 8.425 million Yuan to Xiamen as direct benefits. 
Table 1. Multiple regression results.

\begin{tabular}{cccc}
\hline Variable & Direct effects & Induced effects & Total effects \\
\hline$C$ & $4,241.42$ & $-3,581.90$ & 692.0403 \\
(t-statistics) & $(0.9265)$ & $(-0.8025)$ & $(0.1069)$ \\
& 55.8308 & -3.9105 & 52.2370 \\
Number of exhibition activities & $(0.9379)$ & $(-0.0674)$ & $(0.6204)$ \\
Areas of exhibition & -88.7192 & 120.0448 & 30.6065 \\
& $(-0.7886)$ & $(1.0944)$ & $(0.1923)$ \\
Number of meeting activities & 2.7500 & -1.2655 & 1.4704 \\
& $(1.2624)$ & $(-0.5959)$ & $(0.4772)$ \\
Number of participants & -8.4250 & 50.8135 & 43.4248 \\
& $(-0.0908)$ & $(0.5617)$ & $(0.3308)$ \\
\hline $\mathrm{R}^{2}$ & 0.9779 & 0.9774 & 0.9881 \\
$\overline{\mathrm{R}}^{2}$ & 0.9484 & 0.9473 & 0.9723 \\
\hline
\end{tabular}

Data Sources: Xiamen Convention and Exhibition Industry Development Report

The model of induced effects shows that the number of exhibition activities has a negative impact on Xiamen, and the increase of one unit of the exhibition will reduce the induced benefit of 3.9105 million Yuan for Xiamen. The increase of exhibition area for each unit $\left(10,000 \mathrm{~m}^{2}\right)$ will bring 120.0448 million Yuan of induced benefits to Xiamen. In the meeting activities, each increase in the number of meetings of one unit will reduce the induced benefit of 1.2655 million Yuan for Xiamen, and the impact will be offset by the number of participants. Each increase in the number of participants of one unit (10,000 persons) will increase the induced benefit of 50.8135 million Yuan for Xiamen.

The total effects model shows that the number of exhibition activities, the exhibition area, the number of meeting activities and the number of participants all have a positive impact on Xiamen. The increase of one unit of the exhibition will bring a total benefit of 52.237 million Yuan to Xiamen, while the increase of each unit of the exhibition area will bring a total benefit of 30.6065 million Yuan to Xiamen. In the meeting activities, each increase in the number of meetings of one unit will bring a total benefit of 1.4704 million Yuan to Xiamen, and each increase in the number of participants will bring 43.4248 Yuan to Xiamen as the total benefit.

To sum up, the number of exhibition activities, the exhibition area, the number of meeting activities and the number of participants all have a positive impact on Xiamen's urban economy. However, the increase in the number of meeting activities has a relatively weak impact on the total benefit of the exhibition, because most of the meetings are non-consumption meetings, that is, most of them are gathered by a group of people to exchange and share information, rather than to generate direct income. And meetings cost more to contractors than exhibitions. Some services, such as booth construction and transportation, will be provided by the exhibition contractor. The exhibition area will only provide basic facilities. The meeting relies on the venue to provide a full range of services, including audio, communications, information systems, site layout, etc. In addition, in terms of catering service, the requirements of the exhibition are relatively simple, generally provide basic catering, and the catering service of the meeting is required to be comprehensive, usually have lunch, breakfast, dinner, during the meeting to have refreshments. In other words, the increase in the number of conference activities will only produce a small total benefit, and due to the short stay and relatively small number of participants, the number of meeting activities will not have a positive impact on driving the benefit. Meeting attendance, on the other hand, due to the attendance increased, exhibition contractors will produce more of the service facilities costs, offset the direct benefits of exhibition, but with the increase of the number, drive the benefit is very considerable, the attendance increased, up and down the chain of industries such as hotels, shopping consumption, tourism and other industries will have corresponding income.

\section{Summary and Outlook on Research Results}

Exhibition economy is an important part of Xiamen's urban economy, and the growth of the overall benefit of Xiamen's exhibition contributes to the growth of Xiamen's urban economy. However, in order to study more carefully which part of the overall benefit of exhibition contributes more to Xiamen's urban economy, the exhibition area is divided into meetings and exhibitions. The exhibition focuses on the research of the number and area of exhibition activities, the concentration of meeting activities and the number of meeting activities and the number of participants. Exhibition economic benefit also distinguishes direct economic benefit, induced economic benefit and total economic benefit. The above data analysis shows that the increase of the four 
variables will not bring the corresponding increase of the economy. In addition to the above four variables, there are other factors that affect the growth of economic benefits of Xiamen exhibition, thus affecting the economic benefits of Xiamen city. For example, in 2020, the exhibition industry in Xiamen has suffered serious trauma. The number of exhibition activities, the exhibition area, the number of meeting activities and the number of participants have all decreased significantly. In view of the above problems, this paper proposes corresponding countermeasures to promote the effective and sustainable growth of Xiamen's urban economy.

Xiamen's exhibition facilities have a direct impact on the number and area of conference and exhibition activities, which are directly related to economic benefits as mentioned above. The comprehensive promotion of exhibition facilities not only means the increase of exhibition space, but also means the upgrade of the quality of exhibition facilities, laying a solid foundation for Xiamen exhibition. The outbreak of COVID-19 in 2020 will directly decrease the economic benefit of the exhibition. Xiamen Exhibition and Exhibition should innovate to create online exhibition hosting modes such as Internet+ (Liu and Ding, 2016), actively respond to emergencies, and bring sustainable development to the exhibition economy. Xiamen, as a garden coastal city, has been very hot in tourism, which ensures the flow of people. Tourism is closely related to the convention and exhibition industry, and the convention and exhibition related industries should firmly seize the opportunity to build the convention and exhibition brand with Xiamen characteristics ( $\mathrm{Li}, 2012)$, such as the international marathon held every year and the Zheng Chenggong Cultural Festival, which have created considerable economic benefits for Xiamen.

Exhibition economy is an important part of a city's economic growth point, and it is an inevitable trend to strengthen the discovery of exhibition industry. Enterprises and the government should strengthen cooperation to exert the contribution of exhibition economy accurately, effectively, and sustainably to urban economic development.

\section{References}

1. Li, H.W. (2012). On the Integration of Exhibition Industry in Xiamen. China Business, 36: 234-235.

2. Liu, X., Ding, Z. C., and Yang, Y. X. (2016). Research on the Construction Strategy of Exhibition Metropolitan Area in the Golden Triangle of Southern Fujian Based on the Integration of Xiamen, Zhangzhou, and Quanzhou. Journal of Xiamen Institute of Technology, 4: 34-40.

3. Wu, M. (2016). Research on the Impact of Exhibition Industry on Urban Service Industry Economy-Taking Xiamen as an Example (Unpublished Master's thesis). Fujian Province: Huaqiao University.

4. Zhan, F. P. (2009). Research on the Development of Exhibition Industry in Xiamen Under the Background of Economic Zone on the West Side of the Straits. Journal of Xiamen Institute of Technology, 3: 12-16.

5. Zheng, X. C. (2017). Analysis of Marketing Strategy of Xiamen Exhibition Industry. On Chinese Business, 11: 144146.

6. Zheng, Z. (2014 2020). Xiamen Convention and Exhibition Industry Development Report. Fujian Province: Xiamen Convention and Exhibition Bureau. 